\title{
Medicago truncatula in Interaction with Fusarium and Rhizoctonia Phytopathogenic Fungi: Fungal Aggressiveness, Plant Response Biodiversity and Character Heritability Indices
}

\author{
Marwa Batnini ${ }^{1}$, Imen Haddoudi ${ }^{1,2}$, Wael Taamali ${ }^{3}$, Naceur Djebali ${ }^{4}$, Mounawer Badri ${ }^{5}$, Moncef Mrabet ${ }^{1}$, and \\ Haythem Mhadhbi (i) ${ }^{1, *}$ \\ ${ }^{1}$ Laboratory of Legumes and Sustainable Agrosystems, Centre of Biotechnology of Borj-Cedria, Hammam-Lif, PB 2050, \\ Tunisia \\ ${ }^{2}$ Department of Ecosystem Biology, University of South Bohemia in České Budějovice, České Budějovice, PB 37005, \\ Czechia \\ ${ }^{3}$ Laboratory of Olive Biotechnology, Center of Biotechnology of Borj-Cedria, Hammam-Lif, PB 2050, Tunisia \\ ${ }^{4}$ Laboratory of Bioactive Substances, Center of Biotechnology of Borj-Cedria, Hammam-Lif, PB 2050, Tunisia \\ ${ }^{5}$ Laboratory of Extremophile Plants, Center of Biotechnology of Borj-Cedria, Hammam-Lif, PB 2050, Tunisia
}

(Received on February 4, 2021; Revised on May 6, 2021; Accepted on May 20, 2021)

Fusarium and Rhizoctonia genera are important pathogens of many field crops worldwide. They are constantly evolving and expanding their host range. Selecting resistant cultivars is an effective strategy to break their infection cycles. To this end, we screened a collection of Medicago truncatula accessions against Fusarium oxysporum, Fusarium solani, and Rhizoctonia solani strains isolated from different plant species. Despite the small collection, a biodiversity in the disease response of $M$. truncatula accessions ranging from resistant phenotypes to highly susceptible ones was observed. A17 showed relative resistance to all fungal strains with the lowest disease incidence and ratings while TN1.11 was among the susceptible accessions. As an initiation of the characterization of resistance mechanisms, the antioxidant enzymes' activities, at the early stages of

*Corresponding author.

Phone, FAX) +216-7903850948

E-mail) haythemmhadhbi77@gmail.com

ORCID

Haythem Mhadhbi

https://orcid.org/0000-0003-0786-4269

Handling Editor : Inhwa Yeam

(c) This is an Open Access article distributed under the terms of the Creative Commons Attribution Non-Commercial License (http:// creativecommons.org/licenses/by-nc/4.0) which permits unrestricted noncommercial use, distribution, and reproduction in any medium, provided the original work is properly cited.

Articles can be freely viewed online at www.ppjonline.org. infections, were compared between these contrasting accessions. Our results showed an increment of the antioxidant activities within A17 plants in leaves and roots. We also analyzed the responses of a population of recombinant inbred lines derived from the crossing of A17 and TN1.11 to the infection with the same fungal strains. The broad-sense heritability of measured traits ranged from 0.87 to 0.95 , from 0.72 to 0.96 , and from 0.14 to 0.85 under control, $F$. oxysporum, and $R$. solani conditions, respectively. This high estimated heritability underlines the importance of further molecular analysis of the observed resistance to identify selection markers that could be incorporated into a breeding program and thus improving soil-borne pathogens resistance in crops.

Keywords : biodiversity, Fusarium oxysporum, Medicago truncatula, recombinant inbred lines, Rhizoctonia solani

Fungal diseases are becoming a serious problem to the majority of plants, and associated with severe losses in their production around the world (Farooq et al., 2009). Breeding plants employing the approach of vertical resistance have been used as strategy to reduce these diseases' impacts such as with the rust fungi (Park, 2008). But no strong resistance was identified for many necrotrophic fungi, and this class of pathogens remain a sustainable issue for agriculture in many parts of the world (Anderson 
et al., 2010). Fusarium and Rhizoctonia genera are such pathogens that are difficult to control and require the implication of several approaches to limit their impacts (Anderson et al., 2013; Landa et al., 2004). These pathogens are found globally and mentioned as ubiquitous soil inhabitant that cause severe diseases, such as vascular wilt, Fusarium crown and root rot in host plants which could be responsible of up to $100 \%$ yield loss in susceptible cultivars (Belete et al., 2013; Ramírez-Suero et al., 2010). Fusarium spp. can persist in affected soil as dormant chlamydospores, as microconidia on host plant's surface, and as mycelium or spores on dead tissues for a long period of time (Di Pietro et al., 2003). And $R$. solani exists in nature in the form of vegetative hyphae and sclerotia because of the scarcity of sexual spores and conidia (Tuncer and Eken, 2013).

For these pathogens, alternative approaches such as crop rotation and crop association have been employed as strategies to control their related diseases (Marburger et al., 2015; Peters et al., 2004). Legume crops are constantly used in rotation or association in agricultural systems due to their nutritional importance and protein richness and to their ability to make the soil more fertile by fixing atmospheric nitrogen into the soil (Graham and Vance, 2003; Stagnari et al., 2017; Trabelsi et al., 2012). Moreover, legumes help to control pathogens by breaking their life cycles. But this strategy have met with only little success because of the emerging of new variants that could infect new plant species (Anderson et al., 2013; Djébali et al., 2014).

This emergence of new variants warranted detailed investigations and better understanding of the mechanisms underlying quantitative or partial resistance, and the manipulation of these mechanisms in the attempt to provide enhanced resistance in crop plants and new molecular targets that may be used in crop efficient and durable breeding programs. The legume model plant, Medicago truncatula, is suited for comparative studies of pathogenic interactions (Ramírez-Suero et al., 2010; Rispail et al., 2010). It is a valuable resource to gain insight on important agronomic traits and to understand the mechanisms of resistance to diseases within grain legumes since it is a host plant for several pathogenic fungi that may cause yield losses in legumes fields (Cook, 1999; Rispail and Rubiales, 2014). As such, M. truncatula has been already used to decipher mechanisms of resistance towards biotrophic, hemibiotrophic, and necrotrophic pathogens (Djébali et al., 2009; Prats et al., 2007; Yang et al., 2008).

In Tunisia, soil-borne pathogens are very destructive to legumes and to other diverse crops (Boughalleb and Mahjoub, 2006; Jedidi et al., 2018; Samet et al., 2018). Among the primary methods to controlling these diseases is the selection of resistant cultivars which can be used to dissect the mechanisms and markers of resistance. Utilizing a modal host for broad-host-range fungal pathogens will facilitate this dissection. This study was designed and implemented to (1) assess the disease incidence (DI) of Fusarium oxysporum and Fusarium solani, Vicia faba-infecting isolates (Haddoudi et al., 2021), and of Rhizoctonia solani AG3 isolate, originally isolated from Solanum tuberosum and causes disease on V. faba (Djébali et al., 2014), on a collection of $M$. truncatula accessions and its relevant collection of recombinant inbred lines (RILs), and to (2) estimate the broad-sense heritability of some measured traits which will initiate the elucidation of resistance markers for breeding programs.

\section{Materials and Methods}

Plant material and growth conditions

Parental accessions and RILs. The studied accessions of $M$. truncatula are derived from natural populations from Tunisia (TN1.11, TN6.18, TN8.20, TN7.4, TN14.1, TN12.2, TN6.5, TN4.22, TN4.16, and TN2.12) collected from different eco-geographical sites (Arraouadi et al., 2009, 2011; Lazrek et al., 2009) with two reference accessions Jemalong A17 from the Australian collection and A20 from Moroccan collection (An et al., 2002). The RILs collection was consisted of nine lines $(\mathrm{H} 1, \mathrm{H} 2, \mathrm{H} 4, \mathrm{H} 5$, $\mathrm{H} 6, \mathrm{H} 7, \mathrm{H} 8, \mathrm{H} 9$, and H10), they were created by manually crossing A17, as the male parent, and TN1.11, as the female parent, to produce the F1 generation, which was later selfed. F2 generation was used in self-fertilization and single-seed descent for five generations at the Center of Biotechnology of Borj Cedria (CBBC) in Tunisia. Seeds of RILs are F6-derived.

Germination and growth conditions. Seeds of M. truncatula were surface scarified with sulfuric acid solution for $5 \mathrm{~min}$ and rinsed six times using sterile distilled water. After $2 \mathrm{~h}$ of imbibition in sterile distilled water, seed were transferred into petri dishes containing sterile wet filter paper and germinated in the dark for 3 days at $4^{\circ} \mathrm{C}$ and for $24 \mathrm{~h}$ at $25^{\circ} \mathrm{C}$, always in the dark. The germinated seed were transplanted on medium M (Bécard and Fortin, 1988) in square petri dishes $(12 \mathrm{~cm} \times 12 \mathrm{~cm})$. These dishes were closed with parafilm and placed in a growth chamber at $24^{\circ} \mathrm{C} / 20^{\circ} \mathrm{C}$ at a photoperiod of $16 \mathrm{~h} \mathrm{light} / 8 \mathrm{~h}$ dark. In all experiments, each petri dish contained five seedlings of the same accession, with three replicate. 
Experimental design. The experimental unit consisted of one square petri dish containing five seedlings of the same accession. The screen test of M. truncatula and RILs collections consisted of three replicate of the experimental unit for control (non-infected) plants, and for infected plants (with $F$. oxysporum, F. solani, and $R$. solani), arranged in randomized complete blocks. The data presented are from two independent experiments.

Fungal material, inoculum preparation and disease evaluation

Fusarium spp. F. oxysporum (KLR13) (GenBank reference no. MK615110) and F. solani (KLfl3) (GenBank reference no. MK615111) initially isolated from $V$. faba (Haddoudi et al., 2021) were used in this study. The fungal strains were routinely grown on potato dextrose agar (PDA) at $25^{\circ} \mathrm{C}$ with a photoperiod of $16 \mathrm{~h}$ light and $8 \mathrm{~h}$ obscurity. To prepare the spore suspensions for both strains, six fungal agar-discs $(6 \mathrm{~mm}$ in $\varnothing)$ from 21-day-old culture were sub-cultured in $100 \mathrm{ml}$ liquid potato dextrose broth (PDB) medium at $27^{\circ} \mathrm{C}$ with shaking at $160 \mathrm{rpm}$. The obtained suspensions were filtered and adjusted to $10^{6}$ conidia/ml. To assess the disease on $M$. truncatula accessions, germinated seeds were placed on medium $\mathrm{M}$, at rate of five seedlings per box $(12 \mathrm{~cm} \times 12 \mathrm{~cm})$. Four days later, roots of seedlings were submerged in the spore suspension $\left(10^{6}\right.$ conidia/ $\mathrm{ml}$ ) for $15 \mathrm{~min}$, or in PDB solution for control, and then transferred again on medium M. 21 days post-inoculation (dpi) shoot fresh weight (SFW), root fresh weight (RFW), shoot dry weight (SDW), and root dry weight (RDW) were measured. To closely evaluate the DI, symptoms related to the leaf level and the whole plant level were scored every 4 days from 5 dpi to 21 dpi and to estimate the disease symptom rate (DR) at the leaf and the whole plant level and to calculate the area under the disease progression curve (AUDPC) as described by Bani et al. (2012). Another parameter was calculated as the proportion of dead plants for each accession, the DI.

Rhizoctonia solani AG3. $R$. solani strain, RS1.2, initially collected from $S$. tuberosum L., and infecting $V$. faba (Djébali et al., 2014) was routinely left to culture on PDA medium at $25^{\circ} \mathrm{C}$ under $16 \mathrm{~h}$ of florescent light and $8 \mathrm{~h}$ of obscurity and stored on PDA slants at $4^{\circ} \mathrm{C}$ in the dark. The $R$. solani inoculum was prepared as described by Anderson et al. (2013). Briefly seven agar-discs $(9 \mathrm{~mm}$ in Ø) from 7-day-old culture were sub-cultured in $100 \mathrm{ml}$ PDB medium for 7 days at $25^{\circ} \mathrm{C}$ with shaking. The obtained mycelium, after draining broth, was crushed and homogenized in sterile water, then used for seedlings inoculation at a concentration of $2.2 \mathrm{mg} / \mathrm{ml}$. To inoculate seedlings with $R$. solani, $50 \mu$ l of the obtained mycelium, as described above, was deposited on the roots. Different parameters relating to different features of the disease were measured $21 \mathrm{dpi}$, mentioning SFW, SDW, RFW, and RDW. The number of surviving plants was determined for each square dish which was initially planted with five plantlets, to evaluate the seedlings damping off. These surviving plants were the support to score the number of healthy leaves (NHL), without any symptoms (chlorosis or necrosis), and to determine the RFW which can indicate the direct effect of the fungus.

Antioxidant enzymes assays. After the infection with $F$. oxysporum and R. solani, leaves and roots of A17, TN1.11, $\mathrm{H} 7$, and $\mathrm{H} 6$ were sampled at two time points $1 \mathrm{dpi}$ and 3 dpi. Five hundred $\mathrm{mg}$ of frozen leaves and roots of control and infected seedlings were grinded to a fine powder in a mortar with liquid nitrogen. To extract soluble proteins, the powder was re-suspended, in $2 \mathrm{ml}$ of extraction buffer containing: $50 \mathrm{mM}$ potassium phosphate buffer $(\mathrm{pH}$ 7.8) $0.1 \mathrm{mM}$ EDTA, $0.1 \mathrm{mM}$ PMSF, and $10 \mathrm{mM}$ DTT. The homogenate was then aliquoted in new tubes after centrifugation at $13,000 \times \mathrm{g}$ for $20 \mathrm{~min}$. Extracts were used immediately for enzymatic and protein assays or stored at $-80^{\circ} \mathrm{C}$. Protein concentration was measured using the Bradford (1976) method using a protein assay kit (Bio-Rad, Munched, Germany) and bovine serum albumin as a standard (Sigma, St. Louis, MO, USA). Guaiacol peroxidase (GPOX) activity was determined at $470 \mathrm{~nm}$ during $1 \mathrm{~min}$ ( $\varepsilon=26.6 / \mathrm{mM} / \mathrm{cm}$ ) by its ability to produce $1 \mu \mathrm{mol} / \mathrm{min}$ of guaiacol oxidized in the presence of $\mathrm{H}_{2} \mathrm{O}_{2}$ according to the method described by Anderson et al. (1995). Superoxide dismutase (SOD) activity was assayed according to the method of $\mathrm{Yu}$ and Rengel (1999) in measuring the ability of the enzyme to inhibit the photochemical reduction of NBT (Sigma). The reaction was initiated by the addition of riboflavin, and the absorbance $\left(\mathrm{A}_{560}\right)$, was measured after 10 min of incubation under the light. Catalase (CAT) activity is determined by following the decomposition of $\mathrm{H}_{2} \mathrm{O}_{2}$ at $240 \mathrm{~nm}(\varepsilon=36 / \mathrm{M} / \mathrm{cm})$ (Anderson et al., 1995). Four replicates for proteins content and enzymes activities were used.

Statistical analysis. All statistical analysis was performed with PASW Statistics 18 (SPSS Inc., Chicago, IL, USA). To analyze the significance of differences between the treatments, one way analysis of variance (ANOVA) was performed and Tukey's post hoc test $(P \leq 0.05)$ was applied. To get a clearer idea about the variability of the responses of $M$. truncatula accessions and RILs, we per- 
A

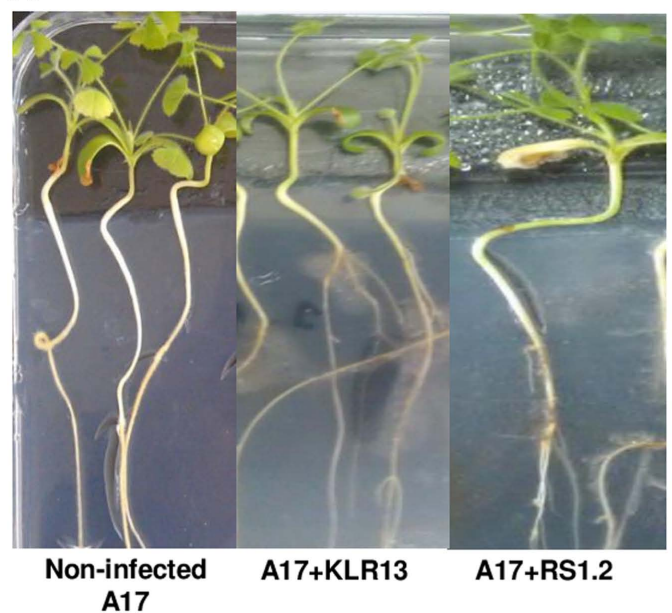

C

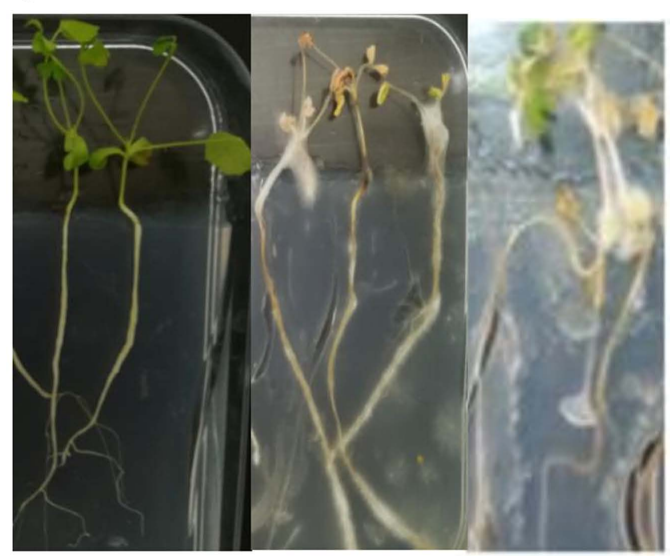

Non-infected TN6.18
B

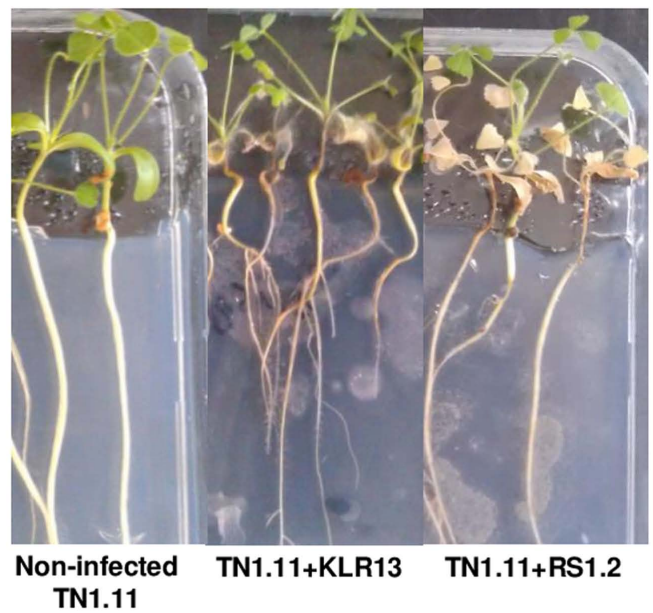

D

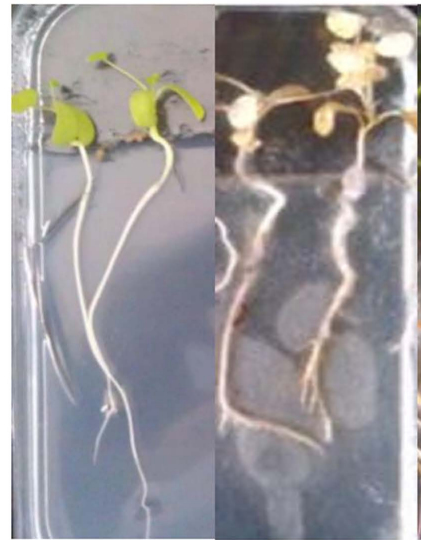

Non-infected A20+KLR13 A20

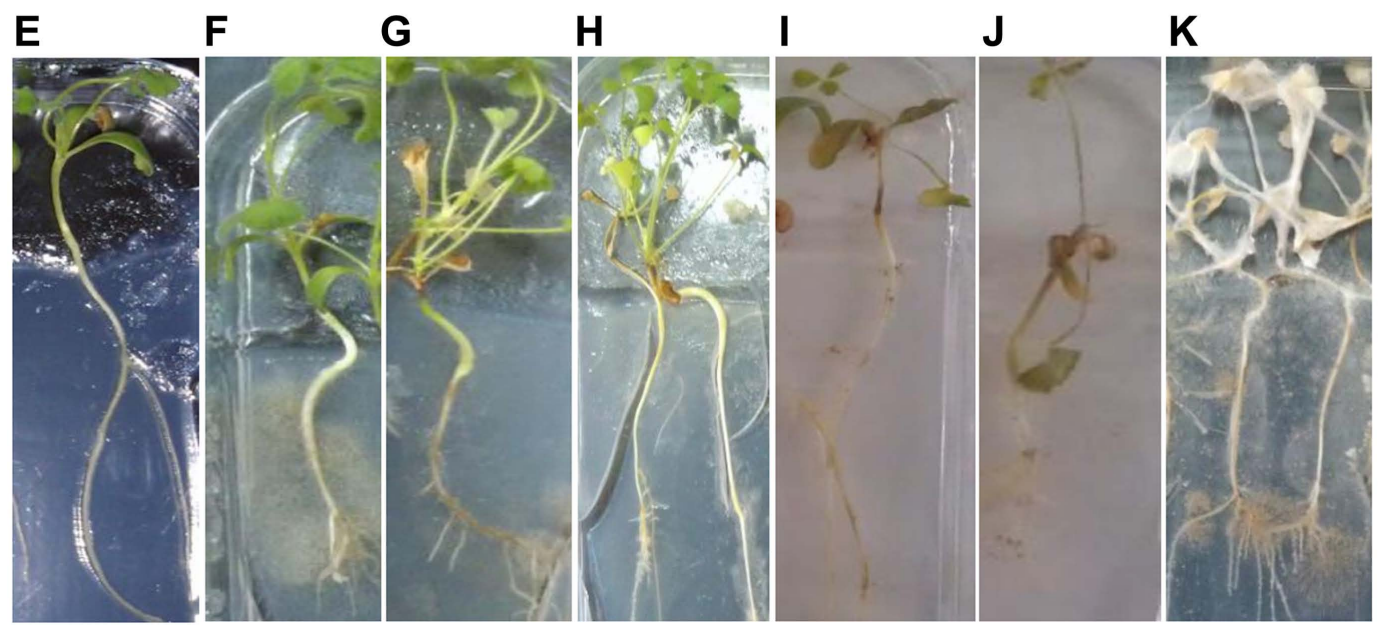

Fig. 1. Disease symptoms induced by Fusarium oxysporum (KLR13), F. solani (KLfl3), and Rhizoctonia solani (RS1.2) on different accessions of Medicago truncatula, 21 days post-inoculation (dpi). (A) A17. (B) TN1.11. (C) TN6.18. (D) A20. (E-K) M. truncatula in interaction with RS1.2: (E) non-infected, (F) A17 showing some root rot, (G) A20 showing root rot and necrosis on cotyledons, (H) TN6.18 showing root rot, dead cotyledons, and chlorosis on first real leaves, (I) TN1.11 showing root rot and crown and beginning of seedlings damping off, (J) TN8.20 showing seedlings damping off, and (K) TN4.22 showing dead plants. Three replicates were analyzed each with five seedlings. 
formed a principal component analysis (PCA). To calculate the broad-sense heritability $\left(\mathrm{H}^{2}\right)$ for all measured parameters in RILs experiment, the variance components $\sigma_{g}^{2}$ (genotypic variance) and $\sigma_{\mathrm{e}}^{2}$ (error variance) were estimated. Genetic variance was calculated considering the line effect as a random effect, while error variance was performed considering the treatment and line as fixed effects.

$H^{2}=\sigma^{2} g /\left(\sigma_{g}^{2}+\sigma_{e}^{2} / K\right)$ Where $K$ is the number of replicates per line.

\section{Results}

Disease development

Fusarium oxysporum. In vitro culture was performed to assess the DI of $12 \mathrm{M}$. truncatula accessions towards $F$. oxysporum (KLR13). Seedlings were inoculated with $F$. oxysporum and parameters were analyzed at $21 \mathrm{dpi}$ or were recorded periodically. Variability in responses to the infection was observed among the studied accessions. F. oxysporum caused severe disease symptoms on the majority of accessions and reduced SDW and RDW (Supplementary Table 1) and no total resistant behavior was revealed. Accessions such as A17 were the least affected with intermediate symptoms on cotyledons and dark-brown discoloration on the roots (Fig. 1A). TN1.11 showed more susceptibility with dead cotyledons, chlorotic first leaves and development of fungal mycelium on the root surface and root growth was reduced (Fig. 1B). Accessions such as TN6.18 and A20 were highly susceptible and they showed early symptoms development on leaves and roots and at 21 dpi all seedlings were dead with massive development of fungal mycelium on all the plantlet (Fig. 1C and D). The

Table 1. Disease ratings of differential lines of Medicago truncatula to Fusarium oxysporum (KLR13) and to F. solani (KLfl3)

\begin{tabular}{|c|c|c|c|c|c|c|}
\hline \multirow{3}{*}{ Line } & \multirow{3}{*}{ Strain } & \multirow{3}{*}{ DI $(\%)$} & \multicolumn{4}{|c|}{ Disease ratings $^{\mathrm{a}}$} \\
\hline & & & \multicolumn{2}{|c|}{ Plant mean disease index } & \multicolumn{2}{|c|}{ Leaves showing symptoms $(\%)$} \\
\hline & & & VI & AUDPC & PS & AUDPC \\
\hline TN1.11 & KLR13 & 33.3 & $3.8 \pm 0.44 b$ & $39.9 \pm 4.71 b$ & $56.2 \pm 6.03 b$ & $583.3 \pm 63.29 b$ \\
\hline A17 & KLR13 & 0 & $1,0 \pm 0.00 \mathrm{~d}$ & $10.5 \pm 0.00 \mathrm{~d}$ & $8.75 \pm 2.29 c$ & $91.8 \pm 24.09 \mathrm{c}$ \\
\hline TN6.18 & KLR13 & 100 & $4.8 \pm 0.06 \mathrm{a}$ & $50.7 \pm 0.63 \mathrm{a}$ & $100.0 \pm 0.00 \mathrm{a}$ & $1,050 \pm 0.00 \mathrm{a}$ \\
\hline TN8.20 & KLR13 & 100 & $5.0 \pm 0.00 \mathrm{a}$ & $52.5 \pm 0.00 \mathrm{a}$ & $100.0 \pm 0.00 \mathrm{a}$ & $1,050 \pm 0.00 \mathrm{a}$ \\
\hline A 20 & KLR13 & 100 & $5.0 \pm 0.00 \mathrm{a}$ & $52.5 \pm 0.00 \mathrm{a}$ & $100.0 \pm 0.00 \mathrm{a}$ & $1,050 \pm 0.00 \mathrm{a}$ \\
\hline TN2.12 & KLR13 & 0 & $2.2 \pm 0.09 \mathrm{~b}$ & $22.6 \pm 1.01 \mathrm{c}$ & $38.4 \pm 9.63 \mathrm{~b}$ & $404.2 \pm 101.12 b$ \\
\hline TN4.16 & KLR13 & 100 & $5.0 \pm 0.00 \mathrm{a}$ & $52.5 \pm 0.00 \mathrm{a}$ & $100.0 \pm 0.00 \mathrm{a}$ & $1,050 \pm 0.00 \mathrm{a}$ \\
\hline TN4.22 & KLR13 & 0 & $2.7 \pm 0.17 b$ & $28.7 \pm 1.84 \mathrm{c}$ & $54.7 \pm 4.76 b$ & $575 \pm 50.00 \mathrm{~b}$ \\
\hline TN6.5 & KLR13 & 100 & $5.0 \pm 0.00 \mathrm{a}$ & $52.5 \pm 0.00 \mathrm{a}$ & $100.0 \pm 0.00 \mathrm{a}$ & $1,050 \pm 0.00 \mathrm{a}$ \\
\hline TN12.2 & KLR13 & 100 & $5.0 \pm 0.00 \mathrm{a}$ & $52.5 \pm 0.00 \mathrm{a}$ & $100.0 \pm 0.00 \mathrm{a}$ & $1,050 \pm 0.00 \mathrm{a}$ \\
\hline TN14.1 & KLR13 & 100 & $5.0 \pm 0.00 \mathrm{a}$ & $52.5 \pm 0.00 \mathrm{a}$ & $100.0 \pm 0.00 \mathrm{a}$ & $1,050 \pm 0.00 \mathrm{a}$ \\
\hline TN7.4 & KLR13 & 100 & $5.0 \pm 0.00 \mathrm{a}$ & $52.5 \pm 0.00 \mathrm{a}$ & $100.0 \pm 0.00 \mathrm{a}$ & $1,050 \pm 0.00 \mathrm{a}$ \\
\hline TN1.11 & KLfl3 & 55.5 & $3.7 \pm 0.17 b$ & $39.9 \pm 1.87 b$ & $68.5 \pm 4.45 b c$ & $719.6 \pm 46.73 \mathrm{bc}$ \\
\hline A17 & KLfl3 & 0 & $1.0 \pm 0.00 \mathrm{~g}$ & $10.5 \pm 0.00 \mathrm{~g}$ & $8.9 \pm 2.22 \mathrm{f}$ & $93.3 \pm 23.83 \mathrm{f}$ \\
\hline TN6.18 & KLfl3 & 44.4 & $3.3 \pm 0.27 b c$ & $34.7 \pm 2.88 b c$ & $56.7 \pm 7.5 \mathrm{bcd}$ & $595.9 \pm 78.81 \mathrm{bcd}$ \\
\hline TN8.20 & KLfl3 & 0 & $1.5 \pm 0.19 \mathrm{fg}$ & $15.9 \pm 2.02 \mathrm{fg}$ & $51.1 \pm 5.77 \mathrm{bcd}$ & $536.6 \pm 60.66 \mathrm{bcd}$ \\
\hline A20 & KLfl3 & 100 & $5.0 \pm 0.00 \mathrm{a}$ & $52.5 \pm 0.00 \mathrm{a}$ & $100.0 \pm 0.00 \mathrm{a}$ & $1,050.0 \pm 0.00 \mathrm{a}$ \\
\hline TN2.12 & KLfl3 KLfl3 & 41.6 & $2.7 \pm 0.11 \mathrm{~cd}$ & $29.3 \pm 1.2 \mathrm{~cd}$ & $53.1 \pm 4.81 \mathrm{bcd}$ & $557.1 \pm 50.60 \mathrm{bcd}$ \\
\hline TN4.16 & KLfl3 & 0 & $2.2 \pm 0.3 \mathrm{def}$ & $23.1 \pm 3.22 \mathrm{def}$ & $68.5 \pm 5.89 \mathrm{bc}$ & $719.2 \pm 61.89 \mathrm{bc}$ \\
\hline TN4.22 & KLfl3 & 100 & $5.0 \pm 0.00 \mathrm{a}$ & $52.5 \pm 0.00 \mathrm{a}$ & $100.0 \pm 0.00 \mathrm{a}$ & $1,050.0 \pm 0.00 \mathrm{a}$ \\
\hline TN6.5 & KLfl3 & 0 & $2.6 \pm 0.00 \mathrm{cde}$ & $27.3 \pm 0.00$ cde & $40.0 \pm 0.00 \mathrm{de}$ & $420.0 \pm 0.00 \mathrm{de}$ \\
\hline TN12.2 & KLfl3 & 0 & $1.0 \pm 0.00 \mathrm{~g}$ & $10.5 \pm 0.00 \mathrm{~g}$ & $20.0 \pm 0.00$ ef & $210.0 \pm 0.00 \mathrm{ef}$ \\
\hline TN14.1 & KLfl3 & 0 & $2.4 \pm 0.08 \mathrm{de}$ & $25.2 \pm 0.85 \mathrm{de}$ & $47.9 \pm 2.83 \mathrm{~cd}$ & $503.1 \pm 29.77 \mathrm{~cd}$ \\
\hline TN7.4 & KLfl3 & 41.6 & $2.9 \pm 0.16 \mathrm{bcd}$ & $31.1 \pm 1.70 \mathrm{bcd}$ & $71.5 \pm 3.61 \mathrm{~b}$ & $750.6 \pm 37.98 \mathrm{~b}$ \\
\hline
\end{tabular}

DI, disease incidence; VI, mean value of visual index of all leaves on an individual plant; AUDPC, area under the disease progression curve; PS, percentage of leaves having symptoms for each individual plants.

'Data are means of three replicates, each with five seedlings; different letters means significant difference between values according to Tukey' HSD range test at $\alpha=5 \%$. Each strain and each parameter was analyzed separately. 
A

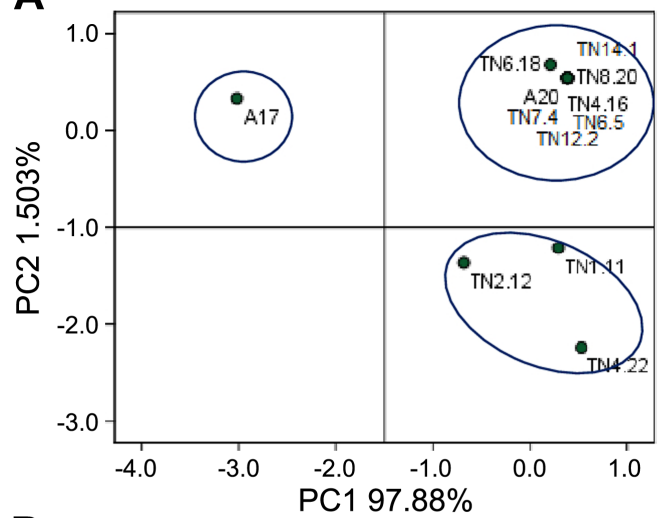

B

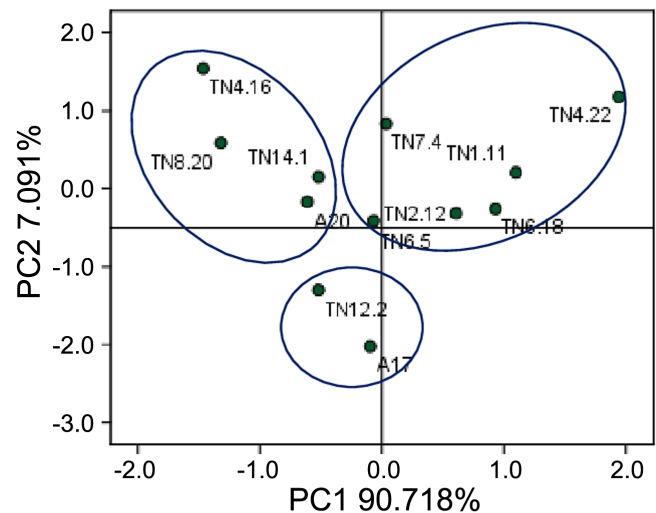

C

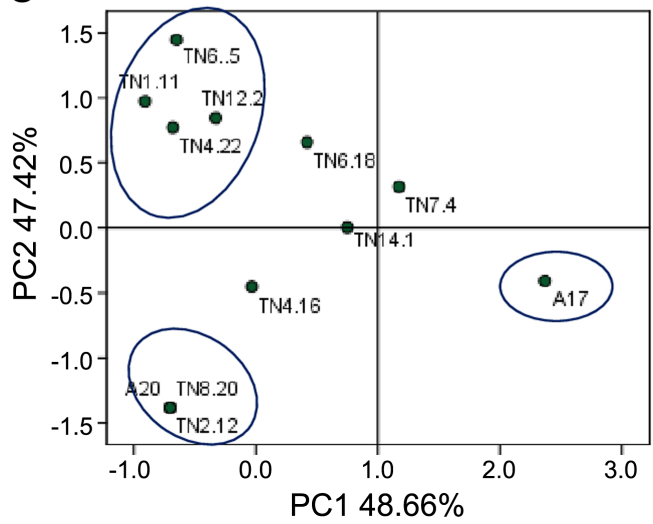

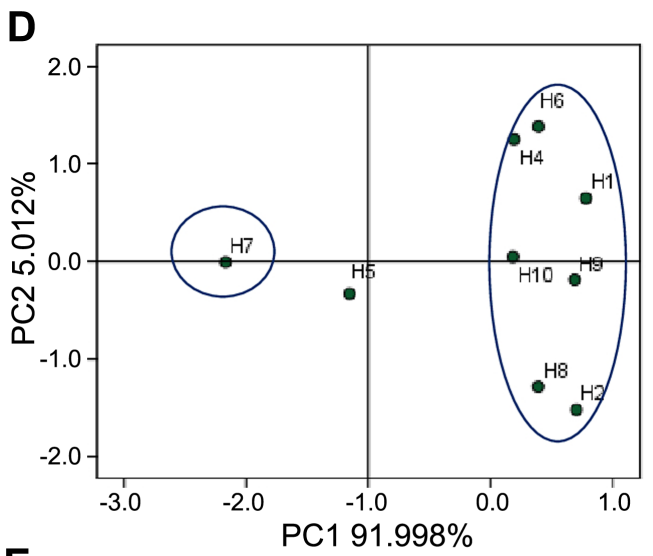

E

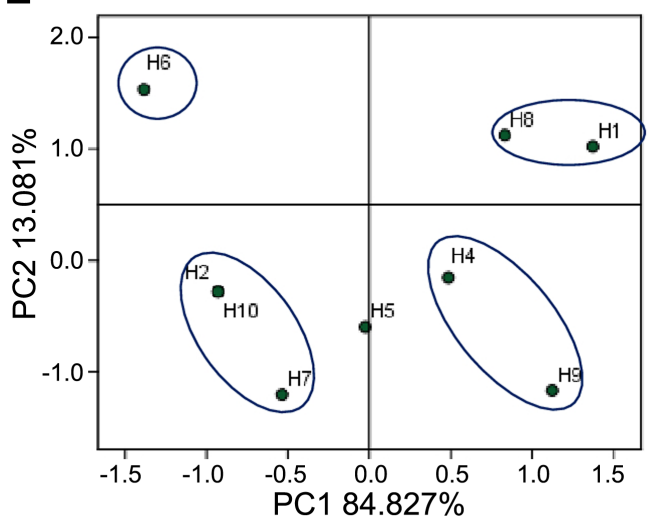

$\mathbf{F}$

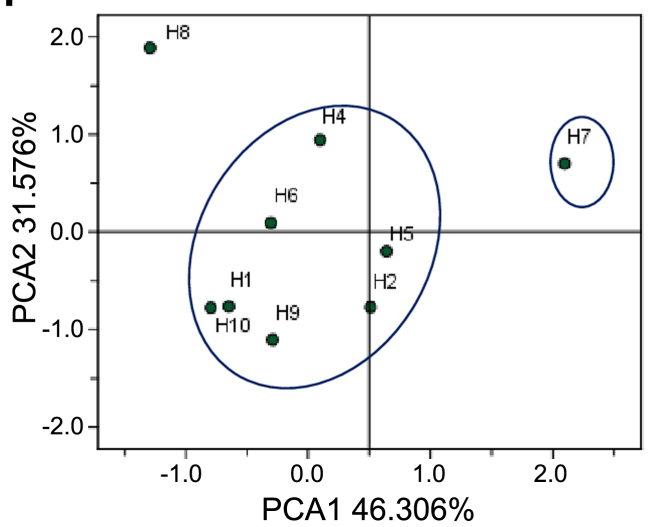

Fig. 2. Principal component analysis (PCA) (A) on five variables measured for the 12 accessions of Medicago truncatula infected with Fusarium oxysporum according mainly to PC1 (97.88\% of the total variance and defined by VI, PS, and their AUDPC); (B) on five variables measured in interaction with $F$. solani according to PC1 $(90.718 \%$ of the total variance and defined by VI, its AUDPC, and DI) and to PC2 (7.091\% of the total variance and defined by PS and its AUDPC); and (C) on four variables measured in interaction with $R$. solani according to PC1 (48.66\% of the total variance and defined by RDW, RFW, and SP) and to PC2 (47.42\% of the total variance and defined by NHL). (D) PCA on four variables measured for the 9 RILs in interaction with $F$. oxysporum according mainly to PC1 (91.998\% of the total variance and defined by VI, PS, and their AUDPC). (E) PCA on four variables measured in interaction with $F$. solani according to PC1 (84.827\% of the total variance and defined by VI, its AUDPC, and DI) and to PC2 (13.081\% of the total variance and defined by PS and its AUDPC). (F) PCA on six variables measured in the interaction with $R$. solani according to PC1 (46.306\% of the total variance and defined by SDW, RDW, SFW, RFW, HL, and SP) and to PC2 (31.576\% of the total variance and defined by SDW, SFW, and SP). Three replicates were analyzed each with five seedlings. VI, mean value of visual index of all leaves on an individual plant; PS, percentage of leaves having symptoms for each individual plants; AUDPC, area under the disease progression curve; DI, disease incidence; RDW, root dry weight; RFW, root fresh weight; SP, number of plants surviving seedling damping off; NHL, number of healthy leaves; RIL, recombinant inbred line; SDW, shoot dry weight; SFW, shoot fresh weight. . 
DI ranged from 0 to $100 \%$, and DR varied from $1.0 / 8.75 \%$ to $5 / 100 \%$ according to mean value of visual index of all leaves on an individual plant (VI) and to percentage of leaves having symptoms for each individual plant (PS) parameters, and from 10.5/91.8 to 52.5/1,050 for their respective AUDPC values (Table 1). To closely segregate contrasting behaviors of lines we performed a PCA taking into account five variables (Fig. 2A). The presentation of the first two components ( $\mathrm{PC} 1=97.88 \%, \mathrm{PC} 2=1.503 \%$ ) showed three groups, the first one is positively correlated with PC1and PC2 showing thereby the highest DI and DR values, the second group is negatively correlated with PC2 and presents lower DI and high DR values, and the last one is negatively correlated with both components and this group contains only A17 with the lowest DI and DR values.

F. solani. F. solani (KLfl3) was less aggressive compared to $F$. oxysporum. A17 showed always a resistant phenotype with symptoms on cotyledons and some root rot (Fig. 1A). Its DI was $0 \%$, DR scores were $1.0 / 8.9 \%$ for VI and PS parameters, the respective AUDPC values were 10.5/93.3
(Table 1). TN1.11 and TN6.18 remained among the susceptible accessions with affected cotyledons and laterformed leaves which in some individual plants were dried and dead, and appearance of root rot for all seedlings (Fig. $1 \mathrm{~B}$ and $\mathrm{C}$ ). DI for the majority of lines ranged from 0 to $41.6 \%$ and DR from $1 / 20 \%$ to $2.9 / 71.5 \%$ for VI and PS parameters and from $10.5 / 210$ to $31.1 / 750.6$ for their respective AUDPC values (Table 1). PCA presented two components, PC1 with $90.718 \%$ of total variance and defined by DI, VI and its AUDPC and PC2 with 7.091\% of total variance defined by PS and its AUDPC (Fig. 2B). A17 was in the group negatively correlated with $\mathrm{PC} 1$ and $\mathrm{PC} 2$ with the lowest DI and DR, in the contrary toTN1.11 which showed higher DI and DR.

M. truncatula as a host for $\boldsymbol{R}$. solani. At $21 \mathrm{dpi}$, moderate pathogenicity of $R$. solani was observed. RS1.2 caused the typical disease symptoms including crown rot and seedlings damping off (Fig. 1G, H, and $\mathrm{K}$ ). The seedlings damping off which was observed only for some accessions such as TN1.11, TN8.20, and A20, occurred until the full expansion of the first true leaf associated with root rot and reduc-

Table 2. Disease ratings of differential inbred lines to Fusarium oxysporum (KLR13) and to F. solani (KLfl3)

\begin{tabular}{|c|c|c|c|c|c|c|}
\hline \multirow{3}{*}{ Line } & \multirow{3}{*}{ Strain } & \multirow{3}{*}{ DI (\%) } & \multicolumn{4}{|c|}{ Disease ratings $^{\mathrm{a}}$} \\
\hline & & & \multicolumn{2}{|c|}{ Plant mean disease index } & \multicolumn{2}{|c|}{ Leaves showing symptoms (\%) } \\
\hline & & & VI & AUDPC & PS & AUDPC \\
\hline H1 & KLR13 & 77.7 & $4.8 \pm 0.85 \mathrm{a}$ & $50.5 \pm 8.99 \mathrm{a}$ & $93.3 \pm 6.66 \mathrm{a}$ & $980.0 \pm 70.00 \mathrm{a}$ \\
\hline $\mathrm{H} 2$ & KLR13 & 0 & $3.7 \pm 0.62 \mathrm{ab}$ & $39.4 \pm 6.60 \mathrm{ab}$ & $61.7 \pm 7.26 b c$ & $647.5 \pm 76.28 b c$ \\
\hline $\mathrm{H} 4$ & KLR13 & 88.8 & $4.5 \pm 0.38 \mathrm{a}$ & $47.4 \pm 4.60 \mathrm{a}$ & $88.8 \pm 7.34 \mathrm{ab}$ & $933.3 \pm 77.16 \mathrm{ab}$ \\
\hline H5 & KLR13 & 0 & $1.7 \pm 0.13 b c$ & $18.5 \pm 1.37 \mathrm{bc}$ & $52.6 \pm 5.09 \mathrm{~cd}$ & $552.8 \pm 53.50 \mathrm{~cd}$ \\
\hline H6 & KLR13 & 77.7 & $5.0 \pm 0.00 \mathrm{a}$ & $52.5 \pm 0.00 \mathrm{a}$ & $90.5 \pm 9.52 \mathrm{ab}$ & $950.0 \pm 100.00 \mathrm{ab}$ \\
\hline $\mathrm{H} 7$ & KLR13 & 0 & $1.4 \pm 0.05 \mathrm{c}$ & $14.6 \pm 0.58 \mathrm{c}$ & $25.8 \pm 2.98 \mathrm{~d}$ & $270.4 \pm 31.33 \mathrm{~d}$ \\
\hline H8 & KLR13 & 0 & $3.3 \pm 0.35 \mathrm{abc}$ & $35.0 \pm 3.70 \mathrm{abc}$ & $62.7 \pm 2.01 \mathrm{bc}$ & $658.7 \pm 36.65 b c$ \\
\hline H9 & KLR13 & 44.4 & $4.2 \pm 0.46 \mathrm{a}$ & $43.7 \pm 4.81 \mathrm{a}$ & $83.3 \pm 4.16 \mathrm{ab}$ & $875.0 \pm 43.75 \mathrm{ab}$ \\
\hline H10 & KLR13 & 50 & $4.2 \pm 0.12 \mathrm{a}$ & $44.5 \pm 1.33 \mathrm{a}$ & $66.3 \pm 4.33 \mathrm{abc}$ & $696.6 \pm 45.52 \mathrm{abc}$ \\
\hline H1 & KLfl3 & 100 & $5.0 \pm 0.00 \mathrm{a}$ & $52.5 \pm 0.00 \mathrm{a}$ & $100.0 \pm 0.00 \mathrm{a}$ & $1,050 \pm 0.00 \mathrm{a}$ \\
\hline $\mathrm{H} 2$ & KLfl3 & 0 & $1.0 \pm 0.00 \mathrm{e}$ & $10.5 \pm 0.00 \mathrm{e}$ & $40.0 \pm 0.00 \mathrm{~cd}$ & $420 \pm 0.00 \mathrm{~cd}$ \\
\hline $\mathrm{H} 4$ & KLfl3 & 30.55 & $3.5 \pm 0.39 \mathrm{bc}$ & $36.3 \pm 4.10 \mathrm{bc}$ & $59.9 \pm 6.73 b c$ & $628.6 \pm 70.69 b c$ \\
\hline H5 & KLfl3 & 0 & $2.6 \pm 0.05 \mathrm{~cd}$ & $27.3 \pm 0.60 \mathrm{~cd}$ & $42.6 \pm 2.70 \mathrm{~cd}$ & $447.7 \pm 28.29 \mathrm{~cd}$ \\
\hline H6 & KLfl3 & 0 & $1.7 \pm 0.04 \mathrm{de}$ & $17.5 \pm 0.44 \mathrm{de}$ & $83.3 \pm 16.66 \mathrm{ab}$ & $875 \pm 175.00 \mathrm{ab}$ \\
\hline $\mathrm{H} 7$ & KLfl3 & 0 & $1.0 \pm 0.00 \mathrm{e}$ & $10.5 \pm 0.00 \mathrm{e}$ & $20.0 \pm 0.00 \mathrm{~d}$ & $210 \pm 0.00 \mathrm{~d}$ \\
\hline H8 & KLfl3 & 66.66 & $4.6 \pm 0.19 \mathrm{ab}$ & $48.45 \pm 2.02 \mathrm{ab}$ & $97.2 \pm 2.77 \mathrm{a}$ & $1,020.8 \pm 29.16 \mathrm{a}$ \\
\hline H9 & KLfl3 & 41.66 & $3.6 \pm 0.66 \mathrm{bc}$ & $38.5 \pm 7.00 \mathrm{bc}$ & $40.0 \pm 10.00 \mathrm{~cd}$ & $420 \pm 105.00 \mathrm{~cd}$ \\
\hline $\mathrm{H} 10$ & KLfl3 & 0 & $1.0 \pm 0.00 \mathrm{e}$ & $10.5 \pm 0.00 \mathrm{e}$ & $40.0 \pm 0.00 \mathrm{~cd}$ & $420 \pm 0.00 \mathrm{~cd}$ \\
\hline
\end{tabular}

DI, disease incidence; VI, mean value of visual index of all leaves on an individual plant; AUDPC, area under the disease progression curve; PS, percentage of leaves having symptoms for each individual plants.

'Data are means of three replicates, each with five seedlings; different letters means significant difference between values according to Tukey' HSD range test at $\alpha=5 \%$. 
tion in the root biomass. All the plantlets of A17 survived seedlings damping off and developed less severe symptoms with limited cankers on the root and brown lesions on cotyledons (Fig. 1F). As a direct effect of the fungus, it reduced significantly RFW and NHL for the majority of the collection (Fig. 3A and B). To discriminate between different groups in the collection based on their responses, we performed a PCA taking into account four variables (Fig. 2C). The obtained graphic showed different groups based on $\mathrm{PC} 1=48.66 \%$ of total variance and $\mathrm{PC} 2=47.42 \%$ of

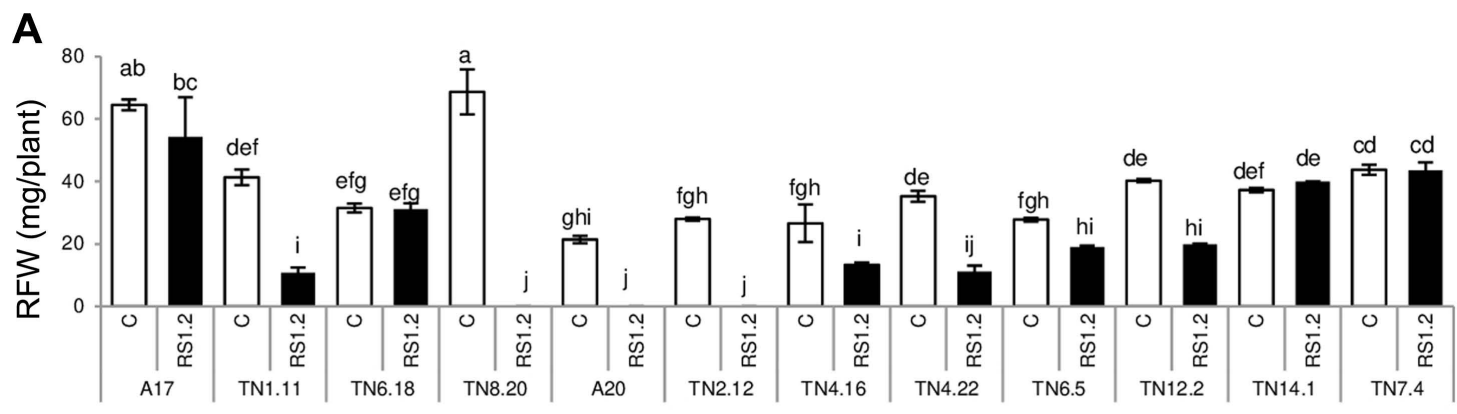

B
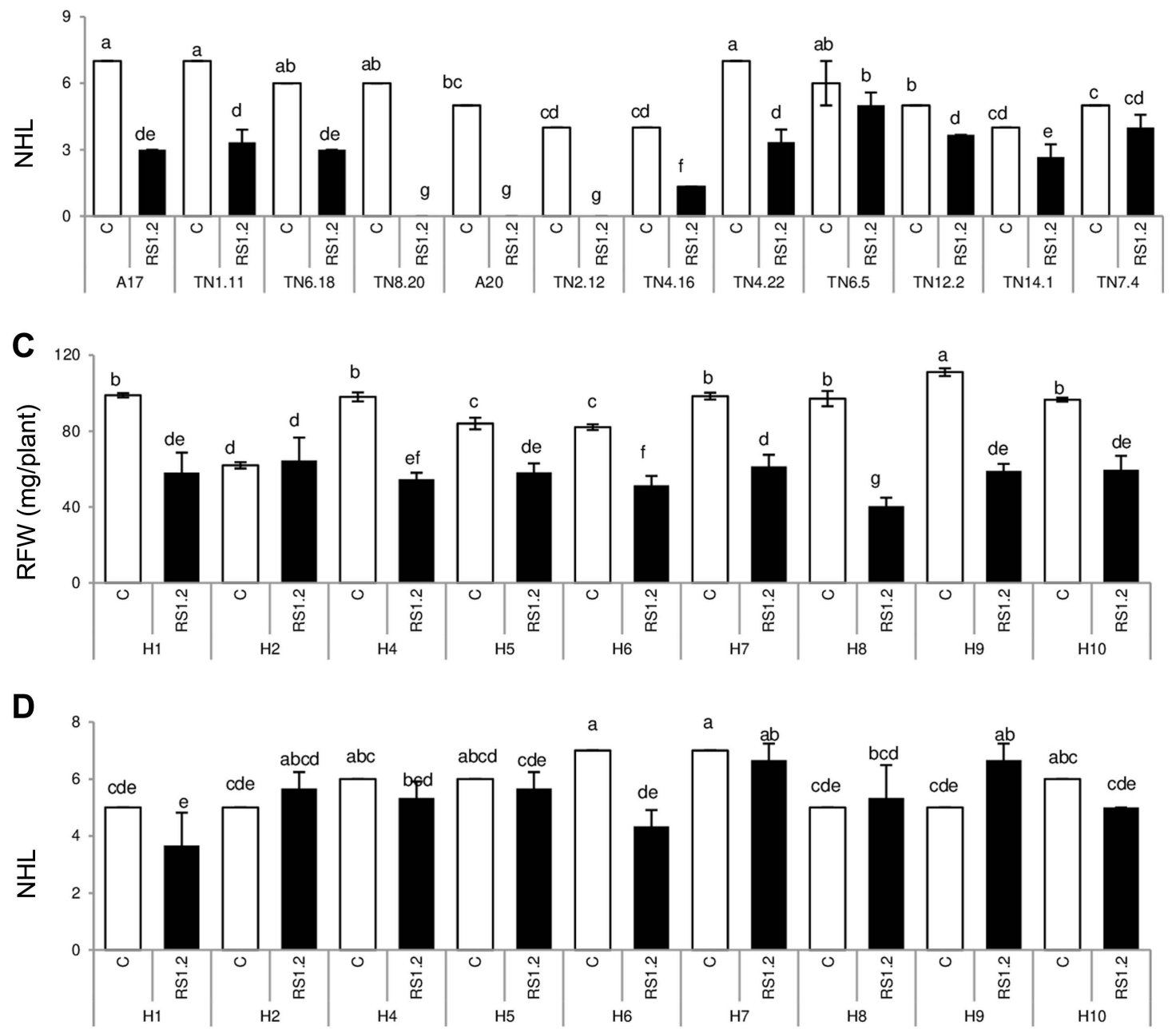

Fig. 3. Performance of Medicago truncatula accessions and recombinant inbred lines (RILs) following infection with Rhizoctonia solani. (A) Root fresh weight (RFW) of M. truncatula accessions. (B) Number of healthy leaves of M. truncatula accessions (NHL). (C) RFW of RILs. (D) NHL of RILs. ( $\square$ ) correspond to non-infected (C, control) plants. ( $\square$ ) correspond to R. solani-infected plants. All measurements were taken at 21 days post-inoculation. Different letters means significant difference between values according to Tukey' HSD range test at $P=0.05$. Data are means of three replicates each with five seedlings. 
total variance. The first one represents the least affected accessions (A17) with the least affected RFW, RDW and surviving plants. The group gathering (TN1.11, TN4.22, TN12.2, and TN6.5) negatively correlated with PC1, thus representing the lowest RFW and RDW. A20, TN8.20, and TN2.12 are the most susceptible accessions with low RFW, RDW, NHL, and surviving plants.
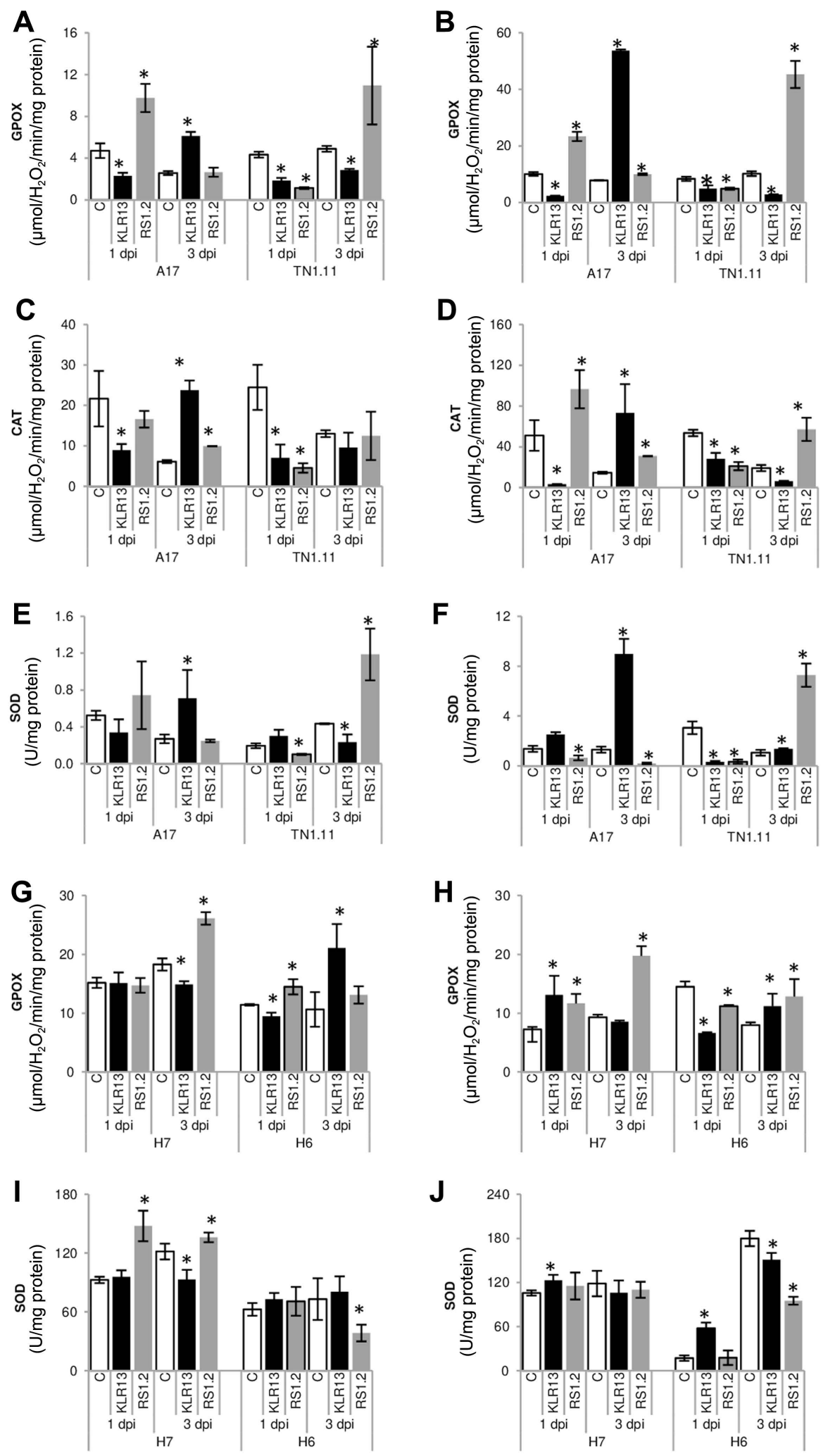

Fig. 4. Effect of the inoculation with Fusarium oxysporum (KLR13) and Rhizoctonia solani (RS1.2) on the activity of guaiacol peroxidase (GPOX), superoxide dismutase (SOD), and catalase (CAT) in leaves and roots of A17, TN1.11, H6, and $\mathrm{H} 7$ at two sampling dates 1 day postinoculation (dpi) and 3 dpi. (A) Activity of GPOX in leaves of A17 and TN1.11. (B) Activity of GPOX in roots. (C) Activity of CAT in leaves. (D) Activity of CAT in roots. (E) Activity of SOD in leaves. (F) Activity of SOD in roots. (G) Activity of GPOX in leaves of H6 and H7. $(\mathrm{H})$ Activity of GPOX in roots. (I) Activity of SOD in leaves. (J) Activity of SOD. ( $\square$ ) corresponds to non-infected plants (C). ( $\square$ ) corresponds to KLR13-infected plants. ( $\square$ ) corresponds to RS1.2-infected plants. *Means significant differences between control and its respective fungal infection at $P=0.05$. Data are means $\pm \mathrm{SD}$ of four replicates. 
Disease assessment of RILs population

$F$. oxysporum. A population of 9 RILs at F6 was tested against $F$. oxysporum. Twenty-one dpi the same parameters, previously recorded with the natural collection of $M$. truncatula, were taken. F. oxysporum developed symptoms on all RILs with DI ranging from $0 \%$ to $88.8 \%$, DR from $1.4 / 25.8 \%$ to $4.8 / 93.3 \%$ according to VI and PS parameters and from $14.6 / 270.4$ to $50.5 / 980$ to their respective AUDPC values (Table 2). The PCA (Fig. 2D) confirmed the distribution given by the DR scores: $\mathrm{H} 7$ was in the group negatively correlated with $(\mathrm{PC} 1=91.998 \%)$ with the lowest values of DI and DR. while the group positively correlated with $\mathrm{PC} 1(\mathrm{H} 1, \mathrm{H} 6, \mathrm{H} 8$, and $\mathrm{H} 4)$ presented the least resistant inbred lines.

F. solani. Infection with $F$. solani developed disease symptoms on all RILs with variability in responses. DI ranged from $0 \%$ to $100 \%$, DR from $1 / 20 \%$ to $5 / 100 \%$ for VI and PS parameters, and from $10.5 / 210$ to $52.5 / 1,050$ for their respective AUDPC values (Table 2). H7 and other lines revealed more resistance to this fungus with the lowest DI and DR (Table 2). While H6 for example showed more susceptibility with high PS and AUDPC. This distribution of RILs was highlighted by the PCA analysis (Fig. 2E) that segregated lines based on two factors: PC1 with $84.82 \%$ of total variance and defined by VI and its AUDPC and DI, PC2 with $13.08 \%$ of total variance defined by PS and its AUDPC.

Susceptibility of RILs population to $R$. solani. SFW, SDW, and RDW results (Supplementry Table 2) showed that $R$. solani showed moderate severity on the inbred collection generally. RS1.2 decreased significantly RFW of all RILs (Fig. 3C). However,no significant effect was obser- ved on the NHL except for H6 (Fig. 3D). To have clearer idea about the distribution of the population, we proceeded to a PCA analysis on six parameters (Fig. 2F). The graphic presented two principal components, $\mathrm{PC} 1=46.306 \%$ and PC2 $=31.576 \%$, the first component gathered mainly the NHL, while SFW, SDW and number of surviving plants were positively correlated with PC1 and PC2. As a consequence, the group situated in the positive side of both components, representing $\mathrm{H} 7$, can be considered as the most resistant inbred line to $R$. solani. While the group negatively correlated with both components represents the least resistant lines mentioning $\mathrm{H} 6, \mathrm{H} 1$, and $\mathrm{H} 10$.

Investigation of oxidative stress response during plant fungi interaction. These analyses were performed on the already selected couples and under infection with $F$. oxysporum and $R$. solani, at two different time points. At 1 dpi (Fig. 4A and B), a significant increase, compared to control conditions, of GPOX activity by $51.69 \%$ and $58.97 \%$ in leaves and roots of A17-RS1.2 interaction was observed respectively, while within TN1.11 a significant decrease in both tissues and under both fungi was observed. Three dpi, GPOX activity increased significantly in leaves and roots of A17-KLR13 and of TN1.11-RS1.2 interactions. CAT activity, at $1 \mathrm{dpi}$, increased in roots of A17 infected with $R$. solani by $88.94 \%$ when compared to control plants. This enhancement was sustained at $3 \mathrm{dpi}$, and accompanied by an increase of the activity in leaves by $38.56 \%$. Also at 3 dpi, CAT activity increased in leaves and roots of A17 infected with $F$. oxysporum increased by $74.27 \%$ and $80.10 \%$, respectively. For TN1.11, in interaction with both fungi, CAT activity marked a decrease (Fig. 4C and D). SOD activity, at $1 \mathrm{dpi}$, significantly increased in roots of A17-F. oxysporum interaction, by $84.55 \%$. At 3 dpi, an en-

Table 3. Means $\pm \mathrm{SD}$, genotypic variance $\partial_{\mathrm{g}}{ }^{2}$, environmental variance $\partial_{\mathrm{e}}{ }^{2}$, and heritability $\left(\mathrm{H}^{2}\right)$ for six traits measured within RILs of Medicago truncatula cultivated under control and Fusarium oxysporum (KLR13) inoculation

\begin{tabular}{|c|c|c|c|c|c|c|}
\hline & SFW & SDW & RFW & RDW & AUDPC (VI) & AUDPC (PS) \\
\hline \multicolumn{7}{|l|}{ Control } \\
\hline Means & $133.66 \pm 32.22$ & $8.53 \pm 2.50$ & $91.99 \pm 13.71$ & $2.99 \pm 0.71$ & 0.00 & 0.00 \\
\hline$\partial_{\mathrm{g}}^{2}$ & 188.326 & 0.69 & 133.117 & 0.149 & - & - \\
\hline$\partial_{\mathrm{e}}^{2}$ & 22.629 & 0.03 & 10.207 & 0.022 & - & - \\
\hline $\mathrm{H}^{2}$ & 0.89 & 0.95 & 0.93 & 0.87 & - & - \\
\hline \multicolumn{7}{|l|}{ KLR13 } \\
\hline Means & $80.55 \pm 44.55$ & $6.50 \pm 2.74$ & $64.80 \pm 28.56$ & $2.74 \pm 0.67$ & $38.47 \pm 14.54$ & $729.39 \pm 239.88$ \\
\hline$\partial_{\mathrm{g}}^{2}$ & 198.607 & 0.712 & 58.169 & 0.085 & 45.646 & $25,443.58$ \\
\hline$\partial_{\mathrm{e}}^{2}$ & 8.080 & 0.069 & 3.576 & 0.012 & 156.154 & $53,728.36$ \\
\hline $\mathrm{H}^{2}$ & 0.96 & 0.91 & 0.94 & 0.87 & 0.72 & 0.81 \\
\hline
\end{tabular}

RIL, recombinant inbred lines; SFW, shoot fresh weight; SDW, shoot dry weight; RFW, root fresh weight; RDW, root dry weight; AUDPC (VI), area under the disease progression curve using VI values; AUDPC (PS), area under the disease progression curve using PS values. 
hancement of this activity by $62.06 \%$ and $85.46 \%$ in leaves and roots was scored. Within TN1.11, inoculation with $R$. solani enhanced SOD by $63.43 \%$ in leaves and by $85.47 \%$ in roots (Fig. 4E and F).

The inbred lines showed a little difference in their antioxidant enzymes activities compared to parental accessions. At $1 \mathrm{dpi}$, roots of $\mathrm{H} 7$ recorded an increase in GPOX activity, compared to control, by $81.38 \%$ under $F$. oxysporum infection and by $61.35 \%$ under $R$. solani (Fig. $4 \mathrm{G}$ ). While in H6, this activity increased in leaves by $26.90 \%$ compared to control under $R$. solani infection. Three dpi, GPOX activity remained high in roots of $\mathrm{H} 7$ in interaction with RS1.2, with concomitant increase in leaves activity as well (Fig. 4G and H). For H6, GPOX in leaves increased under infection with KLR13. SOD activity significantly increased within $\mathrm{H} 7$ leaves, at $1 \mathrm{dpi}$ and after infection with RS1.2, values increased from 92.64 unit/mg protein in control to 147.68 unit/mg protein (Fig. 4I). For roots, SOD activity was 17.14 unit/mg protein and $105.70 \mathrm{unit} / \mathrm{mg}$ protein for control plants of $\mathrm{H} 6$ and $\mathrm{H} 7$, respectively. When infected with $F$. oxysporum, values increased by $70.33 \%$ and $14.12 \%$ in $\mathrm{H} 6$ and $\mathrm{H} 7$ respectively (Fig. $4 \mathrm{~J}$ ).

Heritability. On average all RILs showed similar phenotypes as parental accessions, either the relatively resistant (A17) or the susceptible (TN1.11), under F. oxysporum and $R$. solani infections. To evaluate the importance of scored parameters in the illustration of the noticed phenotypic variability among studied RILs, an estimation of broadsense heritability $\left(\mathrm{H}^{2}\right)$ of these parameters was done. All traits showed high heritability values $(\geq 0.87)$ for control conditions and under $F$. oxysporum inoculation (Table 3 ). The same high levels in heritability were observed in $R$. solani treatments and its control conditions $(\geq 0.76)$ except for SDW (Table 4).

\section{Discussion}

A collection of $M$. truncatula accessions and a population of RILs were screened against $F$. oxysporum, originally isolated from $V$. faba, in a controlled environment using methods previously developed by Bani et al. (2012). Many pathosystems involving $M$. truncatula and root-infecting pathogens were studied to identify the degree of resistance and susceptibility within this plant model (Ben et al., 2013; Djébali et al., 2009; Vailleau et al., 2007). In all these pathosystems, explanatory set of parameters was commonly used to estimate the variability of resistance within $M$. truncatula accessions. This set was based on scoring symptoms such as chlorosis/necrosis on leaves, restriction of the root growth, and the concomitant effect on the whole plant. Our results revealed variability in responses of the studied accessions from relative resistance to high susceptibility based on DI and DR related parameters. As expected from previous studies such as Rispail et al. (2015), our results confirmed that the inoculation with $F$. oxysporum caused typical wilt symptoms, leaf chlorosis and necrosis, complete wilting and death of the plants of the susceptible and the moderately susceptible accessions. Ramírez-Suero et al. (2010) used a M. truncatula-F. oxysporum f. sp. medicagenis pathosystem based on a small hydroponic culture, and after using a visual scale $0-5$ based on the appearance of chlorosis or necrosis on leaves, they identified A17 as the susceptible one. In our study we used a similar pathosystem but with a solid medium instead, after calculating DI and scoring DR with more detailed parameters, we found A17 as the most resistant accession. The rest of the collection showed moderate and high susceptibility with a

Table 4. Means $\pm \mathrm{SD}$, genotypic variance $\partial_{\mathrm{g}}{ }^{2}$, environmental variance $\partial_{\mathrm{e}}{ }^{2}$, and heritability $\left(\mathrm{H}^{2}\right)$ for six traits measured within RILs of Medicago truncatula cultivated under control and Rhizoctonia solani inoculation

\begin{tabular}{|c|c|c|c|c|c|c|}
\hline & SFW & SDW & RFW & RDW & NHL & SP \\
\hline \multicolumn{7}{|l|}{ Control } \\
\hline Means & $133.66 \pm 32.22$ & $8.53 \pm 2.50$ & $91.99 \pm 13.71$ & $2.99 \pm 0.71$ & $5.56 \pm 0.69$ & $5 \pm 0.00$ \\
\hline$\partial_{\mathrm{g}}^{2}$ & 188.326 & 0.69 & 133.117 & 0.149 & 4.539 & 5.252 \\
\hline$\partial_{\mathrm{e}}^{2}$ & 22.629 & 0.03 & 10.207 & 0.022 & 0.499 & 0.686 \\
\hline $\mathrm{H}^{2}$ & 0.89 & 0.95 & 0.93 & 0.87 & 0.90 & 0.88 \\
\hline \multicolumn{7}{|l|}{ RS1.2 } \\
\hline Means & $121.36 \pm 28.34$ & $6.90 \pm 2.77$ & $87.92 \pm 15.22$ & $3.11 \pm 0.64$ & $2.39 \pm 1.54$ & $2.44 \pm 0.84$ \\
\hline$\partial_{\mathrm{g}}^{2}$ & 123.430 & 0.027 & 168.527 & 0.101 & 242.152 & 4.482 \\
\hline$\partial_{\mathrm{e}}^{2}$ & 41.828 & 0.157 & 28.272 & 0.021 & 76.119 & 0.950 \\
\hline $\mathrm{H}^{2}$ & 0.74 & 0.14 & 0.85 & 0.82 & 0.76 & 0.82 \\
\hline
\end{tabular}

RIL, recombinant inbred lines; SFW, shoot fresh weight; SDW, shoot dry weight; RFW, root fresh weight; RDW, root dry weight; NHL, number of healthy leaves; SP, number of plants surviving seedling damping off. 
DI up to $100 \%$. The resistance observed within A17 was concomitant to a significant increase in SOD, CAT, and GPOX activities. This early activation (1 dpi and 3 dpi) can be due to the involvement of the apoplastic reactive oxygen species (ROS) in producing an oxidative burst to impede the progression of the fungus towards conducting vessels (Camejo et al., 2016; García-Limones et al., 2002; Gay and Tuzun, 2000). This underlies the importance of further analyzing the ROS contribution to the observed resistant phenotype.

With $F$. solani, which is a major factor of root rot and Fusarium crown, the tested collection showed variability in their responses. DR parameters showed low pathogenicity of $F$. solani on M. truncatula accessions which may be explained by its specific host range since it showed a high pathogenicity against $V$. faba, its host plant, as presented in the study of Belete et al. (2013). Despite the limited number of accessions used in this study, this M. truncatula collection contained biodiversity in its response, from highly resistant (such as A17) to moderately resistant (such as TN8.20 and TN6.5) to susceptible lines (such as TN1.11 and A20), and this can provide new genetic variation that underlines this wide range of responses to $F$. solani.

$R$. solani is a widespread soil born pathogen, it causes big losses on wide range of crops such as legumes crops (Anderson et al., 2016). In our study we used strain of $R$. solani from AG3 originally isolated from potato and known to infect Faba bean (Djébali et al., 2014) to inoculate our collection of $M$. truncatula. To assess the effect of the infection with $R$. solani, we evaluated two characteristics of the disease phenotype: first, scoring the number of the plants surviving the seedlings damping off, and secondly, estimating the direct effect of the fungus by measuring the RFW and calculating the NHL on each surviving plants. RS1.2 developed the typical symptoms of disease, root rot and crown symptoms, but the accessions responded differently to the infection. Some such as TN1.11, TN8.20, TN4.22, and A20 were found among the most susceptible accessions, while A17 was amongst the least susceptible ones. In a previous study (Anderson et al., 2013), it was reported that M. truncatula is a potential host for AG8 strains of $R$. solani, though AG8 is known for its pathogenicity against cereals, with a biodiversity in responses of different accessions. $R$. solani AG3 is a major pathogen of the potato crop, thus resistance in legume crops would have benefits with respect to effective crop rotation strategies. Our findings showed that $M$. truncatula represents a potential host that can be used to determine the mechanisms acting in these resistant accessions at the cellular and molecular levels.

Previous studies (Ameline-Torregrosa et al., 2008; Ben et al., 2013; Djébali et al., 2009; Vailleau et al., 2007; Yang et al., 2008) used RILs populations derived from the cross between M. truncatula accessions for QTL analysis to facilitate the advancement of genetic studies once biodiversity in responses was observed. We assessed the disease caused by $F$. oxysporum, $F$. solani, and $R$. solani to differentiate between the inbred lines based on their resistance level. The scored parameters revealed similar phenotypes (resistance and susceptible) of RILs compared to the parental lines A17 or TN1.11 and the broad-sense heritability $\left(\mathrm{H}^{2}\right)$ analyses of some measured parameters showed high values in control conditions and under fungal stress. These findings highlight the importance of a QTL mapping to identify loci contributing to moderate resistance to $F$. oxysporum and $R$. solani. Such analysis can provide new insights into how the resistance mechanisms may be employed in crops to enhance resistance to these and other similar intractable pathogens.

In this study two genera of fungi, Fusarium and Rhizoctonia, were used to screen a collection of $M$. truncatula accessions and RILs population. Our results showed a high susceptibility within $M$. truncatula towards $F$. oxysporum, and variability in responses to $R$. solani. This screening allowed us to identify contrasting couple, TN1.11 as susceptible and A17 as relative resistant accession. This resistance was concomitant to an increasing in the activity of the protective antioxidant enzymatic system, peroxidase at an early stage of infection and catalase and superoxide dismutase at another stage of the infection. The contrasting behavior of A17 and TN1.11 towards these fungi was observed within their RILs. The high estimated broadsense heritability of some measured traits underlines the importance of pursuing to the identification of genomic regions (QTLs) which contributed to this resistance, and thus understanding the mechanisms of basal resistance and trying to identify selection markers of resistant cultivars to root pathogens.

\section{Conflicts of Interest}

No potential conflict of interest relevant to this article was reported.

\section{Acknowledgments}

The author acknowledge Jamila Hammemi and Fathi Barhoumi, technicians at Laboratory of Legumes, CBBC, for their technical assistance in the procedure of the screening test.

This work was supported by the [Tunisian Ministry of 
Higher Education and Scientific Research] in the frame of the work program of $\mathrm{L}_{2} \mathrm{AD}-\mathrm{CBBC}$, 2019-2022.

\section{Electronic Supplementary Material}

Supplementary materials are available at The Plant Pathology Journal website (http://www.ppjonline.org/).

\section{References}

Ameline-Torregrosa, C., Cazaux, M., Danesh, D., Chardon, F., Cannon, S. B., Esquerr-Tugay, M.-T., Dumas, B., Young, N. D., Samac, D. A., Huguet, T. and Jacquet, C. 2008. Genetic dissection of resistance to anthracnose and powdery mildew in Medicago truncatula. Mol. Plant-Microbe Interact. 21:6169.

Anderson, J. P., Gleason, C. A., Foley, R. C., Thrall, P. H., Burdon, J. B. and Singh, K. B. 2010. Plants versus pathogens: an evolutionary arms race. Funct. Plant Biol. 37:499-512.

Anderson, J. P., Hane, J. K., Stoll, T., Pain, N., Hastie, M. L., Kaur, P., Hoogland, C., Gorman, J. J. and Singh, K. B. 2016. Proteomic analysis of Rhizoctonia solani identifies infectionspecific, redox associated proteins and insight into adaptation to different plant hosts. Mol. Cell. Proteomics 15:1188-1203.

Anderson, J. P., Lichtenzveig, J., Oliver, R. P. and Singh, K. B. 2013. Medicago truncatula as a model host for studying legume infecting Rhizoctonia solani and identification of a locus affecting resistance to root canker. Plant Pathol. 62:908921.

Anderson, M. D., Prasad, T. K. and Stewart, C. R. 1995. Changes in isozyme profiles of catalase, peroxidase, and glutathione reductase during acclimation to chilling in mesocotyls of maize seedlings. Plant Physiol. 109:1247-1257.

An, J.-M., Lévy, J., Thoquet, P., Kulikova, O., de Billy, F., Penmetsa, V., Kim, D.-J., Debell, F., Rosenberg, C., Cook, D. R., Bisseling, T., Huguet, T. and Dénari, J. 2002. Genetic and cytogenetic mapping of DMI1, DMI2, and DMI3 genes of Medicago truncatula involved in Nod factor transduction, nodulation, and mycorrhization. Mol. Plant-Microbe Interact. 15:1108-1118.

Arraouadi, S., Badri, M., Jaleel, C. A., Djébali, N., Ilahi, H., Huguet, T. and Aouan, M. E. 2009. Analysis of genetic variation in natural populations of Medicago truncatula of Southern Tunisian ecological areas, using morphological traits and SSR Markers. Trop. Plant Biol. 2:122-132.

Arraouadi, S., Badri, M., Zitoun, A., Huguet, T. and Aouani, M. E. 2011. Analysis of $\mathrm{NaCl}$ stress response in Tunisian and reference lines of Medicago truncatula. Russ. J. Plant Physiol. 58:316-323.

Bani, M., Rubiales, D. and Rispail, N. 2012. A detailed evaluation method to identify sources of quantitative resistance to Fusarium oxysporum f. sp. pisi race 2 within a Pisum spp. germplasm collection. Plant Pathol. 61:532-542.
Bécard, G. and Fortin, J. A. 1988. Early events of vesiculararbuscular mycorrhiza formation on Ri T-DNA transformed roots. New Phytol. 108:211-218.

Belete, E., Ayalew, A. and Ahmed, S. 2013. Associations of biophysical factors with faba bean root rot (Fusarium solani) epidemics in the northeastern highlands of Ethiopia. Crop Prot. 52:39-46.

Ben, C., Toueni, M., Montanari, S., Tardin, M.-C., Fervel, M., Negahi, A., Saint-Pierre, L., Mathieu, G., Gras, M.-C., Noël, D., Prospéri, J.-M., Pilet-Nayel, M.-L., Baranger, A., Huguet, T., Julier, B., Rickauer, M. and Gentzbittel, L. 2013. Natural diversity in the model legume Medicago truncatula allows identifying distinct genetic mechanisms conferring partial resistance to Verticillium wilt. J. Exp. Bot. 64:317-332.

Boughalleb, N. and Mahjoub, M. E. 2006. Fusarium solani f.sp. cucurbitae and $F$. oxysporum f.sp. niveum inoculum densities in tunisian soils and their effect on watermelon seedlings. Phytoparasitica 34:149-158.

Bradford, M. M. 1976. A rapid and sensitive method for the quantitation of microgram quantities of protein utilizing the principle of protein-dye binding. Anal. Biochem. 72:248-254.

Camejo, D., Guzmán-Cedeño, Á. and Moreno, A. 2016. Reactive oxygen species, essential molecules, during plant-pathogen interactions. Plant Physiol. Biochem. 103:10-23.

Cook, D. R. 1999. Medicago truncatula: a model in the making! Curr. Opin. Plant Biol. 2:301-304.

Di Pietro, A., Madrid, M. P., Caracuel, Z., Delgado-Jarana, J. and Roncero, M. I. G. 2003. Fusarium oxysporum: exploring the molecular arsenal of a vascular wilt fungus. Mol. Plant Pathol. 4:315-325.

Djébali, N., Elkahoui, S., Taamalli, W., Hessini, K., Tarhouni, B. and Mrabet, M. 2014. Tunisian Rhizoctonia solani $\mathrm{AG}_{3}$ strains affect potato shoot macronutrients content, infect faba bean plants and show in vitro resistance to azoxystrobin. Australas. Plant Pathol. 43:347-358.

Djébali, N., Jauneau, A., Ameline-Torregrosa, C., Chardon, F., Jaulneau, V., Math, C., Bottin, A., Cazaux, M., Pilet-Nayel, M.-L., Baranger, A., Aouani, M. E., Esquerr-Tugay, M.-T., Dumas, B., Huguet, T. and Jacquet, C. 2009. Partial resistance of Medicago truncatula to Aphanomyces euteiches is associated with protection of the root stele and is controlled by a major QTL rich in proteasome-related genes. Mol. PlantMicrobe Interact. 22:1043-1055.

Farooq, M., Wahid, A., Kobayashi, N., Fujita, D. and Basra, S. M. A. 2009. Plant drought stress: effects, mechanisms and management. In: Sustainable agriculture, eds. by E. Lichtfouse, M. Navarrete, P. Debaeke, S. Véronique and C. Alberola, pp. 153-188. Springer, Dordrecht, Germany.

García-Limones, C., Hervás, A., Navas-Cortés, J. A., JiménezDíaz, R. M. and Tena, M. 2002. Induction of an antioxidant enzyme system and other oxidative stress markers associated with compatible and incompatible interactions between chickpea (Cicer arietinum L.) and Fusarium oxysporum f. sp. ciceris. Physiol. Mol. Plant Pathol. 61:325-337. 
Gay, P. A. and Tuzun, S. 2000. Temporal and spatial assessment of defense responses in resistant and susceptible cabbage varieties during infection with Xanthomonas campestris pv. campestris. Physiol. Mol. Plant Pathol. 57:201-210.

Graham, P. H. and Vance, C. P. 2003. Legumes: importance and constraints to greater use. Plant Physiol. 131:872-877.

Haddoudi, I., Mhadhbi, H., Gargouri, M., Barhoumi, F., Romdhane, S. B. and Mrabet, M. 2021. Occurrence of fungal diseases in faba bean (Vicia faba L.) under salt and drought stress. Eur. J. Plant Pathol. 159:385-398.

Jedidi, I., Soldevilla, C., Lahouar, A., Marín, P., González-Jaén, M. T. and Said, S. 2018. Mycoflora isolation and molecular characterization of Aspergillus and Fusarium species in Tunisian cereals. Saudi J. Biol. Sci. 25:868-874.

Landa, B. B., Navas-Cortés, J. A. and Jiménez-Díaz, R. M. 2004. Integrated management of Fusarium wilt of chickpea with sowing date, host resistance, and biological control. Phytopathology 94:946-960.

Lazrek, F., Roussel, V., Ronfort, J., Cardinet, G., Chardon, F., Aouani, M. E. and Huguet, T. 2009. The use of neutral and non-neutral SSRs to analyse the genetic structure of a Tunisian collection of Medicago truncatula lines and to reveal associations with eco-environmental variables. Genetica 135:391.

Marburger, D. A., Venkateshwaran, M., Conley, S. P., Esker, P. D., Lauer, J. G. and An, J.-M. 2015. Crop Rotation and management effect on Fusarium spp. populations. Crop Prot. 55:365376.

Park, R. F. 2008. Breeding cereals for rust resistance in Australia. Plant Pathol. 57:591-602.

Peters, R. D., Sturz, A. V, Carter, M. R. and Sanderson, J. B. 2004. Influence of crop rotation and conservation tillage practices on the severity of soil-borne potato diseases in temperate humid agriculture. Can. J. Soil Sci. 84:397-402.

Prats, E., Llamas, M. J. and Rubiales, D. 2007. Characterization of resistance mechanisms to Erysiphe pisi in Medicago truncatula. Phytopathology 97:1049-1053.

Ramírez-Suero, M., Khanshour, A., Martinez, Y. and Rickauer, M. 2010. A study on the susceptibility of the model legume plant Medicago truncatula to the soil-borne pathogen Fusarium oxysporum. Eur. J. Plant Pathol. 126:517-530.
Rispail, N., Bani, M. and Rubiales, D. 2015. Resistance reaction of Medicago truncatula genotypes to Fusarium oxysporum: effect of plant age, substrate and inoculation method. Crop Pasture Sci. 66:506-515.

Rispail, N., Kal, P., Kiss, G. B., Ellis, T. H. N., Gallardo, K., Thompson, R. D., Prats, E., Larrainzar, E., Ladrere, R., González, E. M., Arrese-Igor, C., Ferguson, B. J., Gresshoff, P. M. and Rubiales, D. 2010. Model legumes contribute to faba bean breeding. Field Crops Res. 115:253-269.

Rispail, N. and Rubiales, D. 2014. Identification of sources of quantitative resistance to Fusarium oxysporum f. sp. medicaginis in Medicago truncatula. Plant Dis. 98:667-673.

Samet, M., Charfeddine, M., Kamoun, L., Nouri-Ellouze, O. and Gargouri-Bouzid, R. 2018. Effect of compost tea containing phosphogypsum on potato plant growth and protection against Fusarium solani infection. Environ. Sci. Pollut. Res. 25:18921-18937.

Stagnari, F., Maggio, A., Galieni, A. and Pisante, M. 2017. Multiple benefits of legumes for agriculture sustainability: an overview. Chem. Biol. Technol. Agric. 4:2.

Trabelsi, D., Ben Ammar, H., Mengoni, A. and Mhamdi, R. 2012. Appraisal of the crop-rotation effect of rhizobial inoculation on potato cropping systems in relation to soil bacterial communities. Soil Biol. Biochem. 54:1-6.

Tuncer, S. and Eken, C. 2013. Anastomosis grouping of Rhizoctonia solani and binucleate Rhizoctonia spp. isolated from pepper in Erzincan, Turkey. Plant Prot. Sci. 49:127-131.

Vailleau, F., Sartorel, E., Jardinaud, M.-F., Chardon, F., Genin, S., Huguet, T., Gentzbittel, L. and Petitprez, M. 2007. Characterization of the interaction between the bacterial wilt pathogen Ralstonia solanacearum and the model legume plant Medicago truncatula. Mol. Plant-Microbe Interact. 20:159-167.

Yang, S., Gao, M., Xu, C., Gao, J., Deshpande, S., Lin, S., Roe, B. A. and Zhu, H. 2008. Alfalfa benefits from Medicago truncatula: the RCT1 gene from $M$. truncatula confers broadspectrum resistance to anthracnose in alfalfa. Proc. Natl. Acad. Sci. U. S. A. 105:12164-12169.

Yu, Q. and Rengel, Z. 1999. Micronutrient deficiency influences plant growth and activities of superoxide dismutases in narrow-leafed lupins. Ann. Bot. 83:175-182. 